\title{
Environmental Aspects Identification Process in Kuwait Oil Company (KOC)
}

\author{
Soud Al-Mutairy, Khulood Yousef, Haitham Fouzy, and Mohammed Safiullah Shareef
}

\begin{abstract}
Kuwait Oil Company (KOC) has successfully implemented HSE management system (HSEMS) in its facilities. HSEMS is a continual cycle of planning, implementing, reviewing and improving the process and actions that an organization undertakes to meet its obligations. KOC HSEMS and Environment Aspect Register were developed to manage the environmental impact associated with a range of operational activities. The HSEMS Guide outlines the general roles and responsibilities for the leadership and all personnel working for and on behalf of the Company for the implementation of the HSEMS in KOC, also to monitor the activities at the facilities which affects the environment. The most important component of this analysis is identification and assessment of the environmental aspect. According to the standard, the environmental aspect is an element of organization activities, products and services that can interact with the environment.

KOC HSEMS Committees agreed to develop (KOC.EV.001Environmental Aspects Identification and Assessment Procedure) with request of Health and Environment Team Leader authorized by KOC HSSE Implementation Committee and approved by KOC HSEMS Procedures Sub-committee. The main objective is to identify whether the environmental aspects and activities in all KOC operations facilities are complying with the regulatory requirement and other obligatory requirements .
\end{abstract}

Index Terms-Environmental aspect, environmental impact, environmental aspects register (EAR), ISO 14001.

\section{INTRODUCTION}

Kuwait Oil Company (KOC) was established in 1934, is one of the largest oil exporter in the world, headquartered in Ahmadi, Kuwait. The Company activities had extended to include exploration operations, on-shore and off-shore surveys, drilling of test wells, and developing of producing fields in addition to crude and natural gas exploration.

Accordingly, as per Environmental Aspects procedure and process (see Fig. 1), every HSE Teams of KOC shall review their environmental aspect register at least annually, and results of the reviews will be provided to all concerned parties and those involved with annual management review of the entire HSEMS. Update and communicate the Environmental Aspects Register (EAR) annually [1].

Recently, KOC has successfully awarded with External Certification for the ISO14001:2004 standard for

Manuscript received August 11, 2015; revised December 29, 2015.

Soud Al-Mutairy and Khulood Yousef are with KOC, Kuwait (e-mail: SAMutairi@kockw.com).

Haitham Fouzy is with NAPESCO, Kuwait (e-mail: HFouzy@kockw.com)

Mohammed Safiullah Shareef is with KN, Kuwait (e-mail: MSafiullah@kockw.com). environmental management and the OHSAS 18001:2007 standard for occupational health and safety management [2], [3].

Each KOC Group is maintaining an Environmental Aspects Register (EAR). Based on the operational activities, environmental aspects and impacts that arises from the activities were identified. Environmental Aspects are evaluated considering both the potential environmental impact and severity of the aspect and the likelihood of its occurrence. Level of impact is a product of severity score and likelihood score. Each environmental aspect is assigned a rating of High, Medium or Low based on relative impact. Environmental aspects with High impact rating requires 'Significant Environmental Aspects Management Program' to reduce its impact.

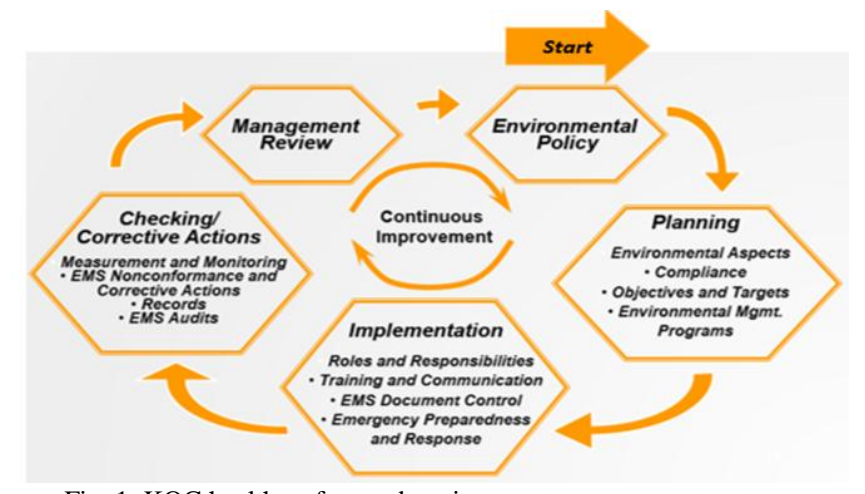

Fig. 1. KOC health, safety and environment management system.

\section{ENVIRONMENTAL ASPECT IMPACT}

\section{A. Environmental Aspect}

An element of an organization's activities, products or services that can interact with the environment.

\section{B. Environmental Impact}

Any change to the environment, whether adverse or wholly or partially resulting from an organization's activities, products or services.

\section{Environmental Aspects Register (EAR)}

A controlled document which records all of the environmental aspects that have been identified, together with their significance rating and control measures.

\section{Aspects Identification}

In order to make aspect identification more manageable, the Groups activities is assessed based on division as follows, provided all areas and functions are included:

This division is done on any basis as follows:

- Process units (e.g. Manifold, Dehydration unit, Desalter). 
- Geographical areas (e.g. Office, Workshops, lay down areas); and

- Activities (e.g. Flaring, Drilling, Vehicle movements)

Aspects identification is based on potential impacts to environment:

- Emission to air including Green House Gases

- Discharges to water (or sewer)

- Spills/releases to land

- Management/disposal of hazardous and non-hazardous waste

- Water use

- Fuel and energy use

- Use of raw materials and natural resources (renewable/nonrenewable)

- Use of chemicals etc.

\section{E. Environmental Impact Associated with the Following} KOC Operational Activities

- Loading of oil tankers

- Storage and use of chemicals

- Discharge of wastewater

- Drilling

- Handling, treatment and disposal of wastes Oil/Sludge

Solids

Metals

Chemicals etc.

- Site construction activities

- Tank cleaning

- Maintenance and overhaul

- Gardening

- Flaring etc.

TABLE I: ILLUSTRATIONS OF ASPECTS AND IMPACTS

\begin{tabular}{|c|c|c|}
\hline $\begin{array}{c}\text { Operational } \\
\text { Activity }\end{array}$ & Environmental Aspects & Environmental Impacts \\
\hline Flaring & $\begin{array}{l}\text { - Gaseous emission to } \\
\text { atmosphere }\left(\mathrm{CO}_{2}, \mathrm{CO} \text {, }\right. \\
\mathrm{NO}_{\mathrm{x}}, \mathrm{SO}_{2}, \mathrm{CH}_{4} \& \\
\text { un-burnt hydrocarbons })\end{array}$ & $\begin{array}{l}\text { - Contribute to global } \\
\text { warming } \\
\text { - NOx and SO2 contribute } \\
\text { to acidification. } \\
\text {-VOC and NOX } \\
\text { precursors to } \\
\text { photochemical smog } \\
\text { formation }\end{array}$ \\
\hline $\begin{array}{l}\text { Storage of } \\
\text { crude oil }\end{array}$ & Oil spill & $\begin{array}{l}\text { - Hydrocarbon entering } \\
\text { the marine/land } \\
\text { environment. } \\
\text { - Atmospheric impacts } \\
\text { from VOCs }\end{array}$ \\
\hline $\begin{array}{c}\text { waste } \\
\text { disposal }\end{array}$ & $\begin{array}{c}\text { disposal of waste } \\
\text { materials }\end{array}$ & $\begin{array}{l}\text { Ground contamination \& } \\
\text { water pollution from } \\
\text { leachate } \\
\text { Air pollution from } \\
\text { incineration } \\
\text { Transport impacts } \\
\text { associated with shipping } \\
\text { to disposal facilities }\end{array}$ \\
\hline
\end{tabular}

As for identification of the environmental aspects and impacts, it is suggested to attach the results to the procedure of identification and assessment of the environmental aspects. At the end of works, this kind of attachment will be a complex set of information on the environmental aspects and impacts and the assessment of their significance for the plant. According to the general tendency for parameterization of management systems [4], [5], nowadays the point-based method is recommended for assessment of the environmental aspects.

When identifying environment aspects, consideration should be given to:

- Normal operating conditions;

- Abnormal operating conditions;

- Incidents, accidents and potential emergency situations;

- Past activities; and

- Planned activities

To ensure identification of all environmental aspects, review teams will have access to all relevant information regarding facility operation, processes, and other activities, including, but not limited to:

- Facility drawings;

- Process flow diagram;

- Process descriptions;

- Materials lists and SDS

- Incident reports

- Audit reports;

- Emissions and Waste reports.

Table I illustrate some aspects associated with Oil \& Gas operational activities [6].

\section{ENVIRONMENTAL ASPECTS EVALUATION}

Evaluation shall be carried out on an impact basis, taken into consideration both the potential environmental impact \& Severity (see Table II) of the aspect and the likelihood (see Table III) of its occurrence. When more than one impact (Air Pollution, Sea/Water Pollution, Land Contamination, Resource depletion, Flora \& Fauna/Community Impact) is applicable to given aspect, the highest (most severe) raking will be used for that aspect.

The common way for assessing the environmental aspects and impacts is to use elements of the risk analysis [6], [7]. The established methodology assumes considering two parameters: probability of event occurrence (impact) on the environment as a result of previously identified aspect and severity (results) of occurrence of this event (impact). If the event occurrence is sure, its frequency is considered (also the continuity of occurrence).

TABLE II: SEVERITY SCORING FOR ENVIRONMENTAL ASPECTS

\begin{tabular}{|c|l|c|}
\hline $\begin{array}{c}\text { Severity of } \\
\text { Environmental } \\
\text { Impact }\end{array}$ & \multicolumn{1}{|c|}{ General Definition } & $\begin{array}{c}\text { Severity } \\
\text { Score }\end{array}$ \\
\hline Negligible & $\begin{array}{l}\text { No negative impact on environment } \\
\text { or almost immediate recovery }\end{array}$ & 1 \\
\hline Slight & $\begin{array}{l}\text { Minor negative impact on } \\
\text { environment without any noticeable } \\
\text { effects }\end{array}$ & 2 \\
\hline Moderate & $\begin{array}{l}\text { Moderate negative impact on } \\
\text { environment with short term effects }\end{array}$ & 3 \\
\hline High & $\begin{array}{l}\text { High negative impact on } \\
\text { environment with potential long } \\
\text { term effects }\end{array}$ & 4 \\
\hline Very High & $\begin{array}{l}\text { Severe negative impact on } \\
\text { environment with long term effects }\end{array}$ & 5 \\
\hline
\end{tabular}

A point-based method for assessing the environmental aspects assumes replacing the graduated descriptions of the significance of the event occurrence probability and effects (environmental impact) with assigned numbers of the point key. The point key is completely random in the method of 
parameters gradation and should result from a detailed analysis of all identified environmental aspects. To underline the parameter significance, it is allowed to use a non-linear scale and expand the method by additional parameters assessed in the same mode. The level of impact can be calculated by multiplying 'Severity' into Likelihood Score'

\section{Level of Impact $=$ Severity Score $\times$ Likelihood Score}

Each environmental aspect shall be assigned a rating of High, Medium, or Low based on relative impact, (see Table IV) - Environmental Aspect Relative Impact Matrix.
TABLE III: LIKELIHOOD OF OCCURRENCE SCORING FOR ENVIRONMENTAL ASPECTS

\begin{tabular}{|c|l|c|}
\hline $\begin{array}{c}\text { Likelihood of } \\
\text { Occurrence }\end{array}$ & \multicolumn{1}{|c|}{ General Definition } & $\begin{array}{c}\text { Likelihood } \\
\text { Score }\end{array}$ \\
\hline $\begin{array}{c}\text { Very } \\
\text { Unlikely }\end{array}$ & $\begin{array}{l}\text { Occurred or heard of in the O\&G } \\
\text { industry but never occurred in the } \\
\text { Company }\end{array}$ & 1 \\
\hline Unlikely & $\begin{array}{l}\text { Has occurred in the company but not } \\
\text { more than once in 10 Years }\end{array}$ & 2 \\
\hline Possible & $\begin{array}{l}\text { Has occurred in the company not more } \\
\text { than once in 5Years }\end{array}$ & 3 \\
\hline Likely & $\begin{array}{l}\text { Has occurred in the company not more } \\
\text { than once per years }\end{array}$ & 4 \\
\hline Very Likely & $\begin{array}{l}\text { Has occurred more than once per years in } \\
\text { the company }\end{array}$ & 5 \\
\hline
\end{tabular}

TABLE IV: ENVIRONMENTAL ASPECTS RELATIVE IMPACT MATRIX

\begin{tabular}{|c|c|c|c|c|c|c|}
\hline & \multicolumn{5}{|c|}{ Severity } \\
\hline & & Negligible (1) & Slight (2) & Moderate (3) & High (4) & Very High (5) \\
\hline \multirow{5}{*}{ 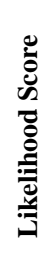 } & Very Unlikely (1) & LOW (1) & LOW (2) & LOW (3) & LOW (4) & MEDIUM (5) \\
\hline & Unlikely (2) & LOW (2) & LOW (4) & LOW (6) & MEDIUM (8) & MEDIUM (10) \\
\hline & Possible (3) & LOW (3) & LOW (6) & MEDIUM (9) & MEDIUM (12) & HIGH (15) \\
\hline & Likely (4) & LOW (4) & MEDIUM (8) & MEDIUM (12) & HIGH (16) & HIGH (20) \\
\hline & Very likely (5) & LOW (5) & MEDIUM (10) & HIGH (15) & HIGH (20) & HIGH (25) \\
\hline
\end{tabular}

TABLE V: SignificANT ENVIRONMENTAL ASPECTS MANAGEMENT PROGRAM [8]

\begin{tabular}{|l|l|l|l|l|l|l|l|l|}
\hline \multicolumn{8}{|c|}{ Appendix A: Significant Environmental Aspects Management Program (Template) } \\
\hline \multirow{2}{*}{ SL.\# } & $\begin{array}{l}\text { Ref.\# Env. } \\
\text { Aspect }\end{array}$ & $\begin{array}{l}\text { Objective } \\
\text { (Control } \\
\text { Measure) }\end{array}$ & Units & \multicolumn{3}{|c|}{ Targets } & Monitoring & Status \\
\cline { 2 - 6 }
\end{tabular}

\section{DETERMINATION OF ENVIRONMENTAL ASPECT SIGNIFICANCE}

All those environmental aspects with an impact rating of High will be designated Significant Environmental Aspects.

The relative impact ranking can be used as a guide to the level of management required to address the impact presented by an aspect.

The significant environmental aspects require Environmental Management Program (see Table V) including monitoring in order to reduce its impact. The groups are required to use the standard template for "Significant Environmental Aspects Management Program”.

- All those environmental aspects with an impact rating of Medium requires periodic review of existing \& additional control(s) if any, and monitoring process in order to maintain or lower the level of impact.

- All those environmental aspects with an impact rating of Low requires periodic review of the existing control measures, to ensure the impact level low is maintained.

\section{ENVIRONMENTAL ASPECTS REGISTERS (EAR)}

Environmental aspect identification and evaluation shall be recorded in an Environmental Aspects Register (EAR). The EAR is a controlled Microsoft Excel spreadsheet that enables all aspects to be clearly identified along with key information regarding their control and management. The template for the Environmental Aspect Register. All groups are utilizing this standard template to ensure that aspects are evaluated consistently across KOC.

The company groups prepare and upload their controlled copy of Environmental Aspect Register in their respective intranet portal and shall be accessible to all company employees.

The group Managers with the support of HSE Teams is formally reviewing the environmental aspect register annually, and results of the reviews are provided to all concerned parties and those involved with annual management review of the entire HSEMS. The group Managers provide resources to assemble a multidisciplinary team consisting of Team Leaders, senior engineers, operations and maintenance supervisors, an HSE Specialist and others as needed to form a group with comprehensive knowledge of all asset facilities and activities to prepare, review and update the Environmental Aspects Register.

The EARs will also be amended immediately whenever:

- There are significant changes to activities, company policy or regulations which result in the addition or deletion of environmental aspects; or

- The significance or management of an aspect changes due to new information from monitoring, audits, incident reports, etc. 
- Any addition, deletion or changes in the regulations

All amendments to the EARs will be communicated to groups staff whose job functions may be directly involved with the new or modified environmental aspect. Appropriate training is provided for all additional controls associated with the aspect/impact.

Any change or amendment in Environmental Aspect Register is carried out as per company HSEMS Document Control Procedure [9] and HSE Records Management Procedure. Records of amendments are noted in the controlled EAR Microsoft Excel spreadsheets [10].

KOC has standardized the format of KOC HSEMS Document KOC.EV.002 - Environmental Aspects Register (EAR), across KOC to control, consistent and ease of queries on the document. .

\section{PERFORMANCE AND AUditing OF ENVIRONMENTAL ASPECTS IDENTIFICATION PROCESS}

\section{A. Conducting Yearly Workshops for Reviewing Aspects for All Groups}

HSE Teams are conducting workshops annually to review the aspects and evaluate the rating based on the initiative implemented by each groups. Further, new technology recommendations has been provided to reduce/control the impact and that updated in the next revisions.

\section{B. Internal and External Audit}

KOC has been conducting internal audits annually for maintaining, implementing and recording the Environmental Aspects Registers (EAR) in group levels.

KOC has successfully awarded External Certification for the ISO14001:2004 standard for environmental management and the OHSAS 18001:2007 standard for occupational health and safety management.

\section{Environmental Aspects Inspections}

HSE Teams have schedule to conduct weekly inspections to monitor the aspects and ensure that the variations of aspects affects the environment.

\section{CONCLUSION}

Allover we can conclude that the company Environmental Aspects Register procedures are designed to be mutually supportive; they can also be used independently of each other to achieve environmental goals. The whole Environmental Aspects Register procedures provide management tools for company to manage their environmental aspects and assess their environmental performance. The Identification of environmental aspects and impacts is a key part of an EMS, which includes procedures for identification, and updating of aspects and impacts in order to comply with regulatory requirements.

Together, these tools can provide significant tangible economic benefits, including the following:

- Reduced raw material/resource use

- Reduced energy consumption

- Improved process efficiency
- Reduced waste generation and disposal costs

- Utilization of recoverable resources.

Of course, associated with each of these economic benefits are distinct environmental benefits too as:

- All the environmental aspects register is documented for the future.

- Help solidify/strengthen existing Environmental Policy.

- A way for KOC to do the right thing without the need for additional regulations, involvement, intrusion.

- Environmental management excellence.

- Reduction in environmental compliance violations

- Increased complexity of the regulatory requirements.

- Reduction in health \& safety hazards, risks = less injuries

- Assist in the application and implementation of environmental legislation.

- Framework for continuous improvement of environmental performance and compliance with all aspects of technical operations, such as the for the operation areas at company, environmental control and other status.

- Reduce costs (evaluate all opportunities to reduce costsm and save energy and materials) consumption.

- Reduce the size of hazardous chemicals and other products used or extracted

- Improve the health and safety of workers, knowledge and training needs, which would result in service development and improvement of production.

\section{REFERENCES}

[1] TL Health and Environment, "Environmental aspects identification and assessment procedure 2004 (Doc. No. KOC.EV.001), " vol. 1, pp. 9-12, 2013.

[2] ISO 14001: 2004 - Environmental Management System Requirements with Guidance for Use.

[3] Manager HSE, "KOC HSE audit, inspection and self-assessment procedure (Doc. No. KOC.GE.016)," vol. 1, p. 6, 2012.

[4] Z. Środowiskowe, Komentarz do Norm Serii ISO 14000. Polski Komitet Normalizacyjny, Warszawa, 2005.

[5] A. Gach, Seria "ISO 9000: 2000 nowoczesne zarządzanie jakością," Wydawnictwo Verlag Dashöfer, Warszawa, 2003.

[6] TL Health and Environment, "KOC environmental aspects register (Doc No. KOC.EV.002)," p. 1, 2013

[7] TL Health and Environment, "Environmental management framework in KOC (KOC.EV.014)," 2014.

[8] TL Health and Environment Appendix B - Significant Environmental Aspects Management Program (Template/Format), p. 12, 2013.

[9] TL HSE System, "KOC HSEMS document control procedure KOC.GE.013,” 2013.

[10] TL HSE System, "HSE records management procedure (KOC.GE.045),” 2014.

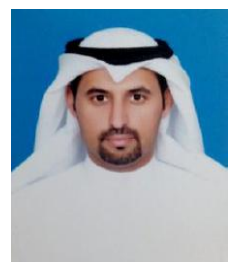

Soud Al-Mutairy was born in Kuwait on April 9 1977. He got the bachelor of science in chemical engineering, Kuwait University, Kuwait, 2000 majored in chemical engineering. He is working with Kuwait Oil Company (KOC) for past 13 years (2002 to 2014) in HSE team of S\&EK, West Kuwait and North Kuwait Directorates. From 2015 to present, he is a TPL specialist, health, safety and environment (South East

Kuwait), KOC from 2008 to 2015 . He is a senior environmental engineer, Kuwait Oil Company, Kuwait, 2002 - 2008, an environmental engineer, Kuwait Oil Company, Kuwait, 2001 - 2002. He is an environment engineer, Environmental Department, Ministry of Oil, Kuwait.

Khulood Yousef was born at Kuwait. She got the bachelor of science in chemical engineering, Kuwait University, Kuwait, 2000, majored in chemical engineering. She is working with Kuwait Oil Company (KOC) for past 14 years (2002 to 2015) in health, safety and environment (HSE group), KOC. 2008 to present, she is a senior environmental engineer, Kuwait Oil Company, Kuwait. 


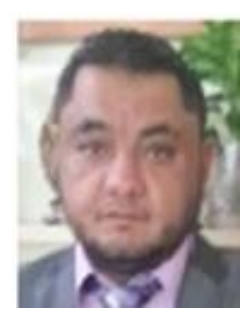

Haitham A. Fouzy was born at Kuwait on March 23 1969. He got the PhD Degree in environmental science from Dr. Bambu University Augrangabad, India in year 1999 majored in environmental science. $\mathrm{He}$ is working with National Petroleum Services Company for past 08 years (2007 to 2015) Kuwait. $\mathrm{He}$ was an environmental engineering specialist, National Petroleum Services Company for past 07 years (2007 to 2015) He was a Kuwait environmental consultant, BDG Company, Kuwait from (2004-2007). He was an environmental engineering, Enviro Company, India from (1999-2004). He worked as a lecture assistant for the subjects of environmental pollution in "Dr BAM.U University", India from 1996 to 1999.
Mohammed Safiullah Shareef was born at India. He got the bachelor of technology in chemical engineering, JNTU, India, 2007, majored in chemical engineering. He is working with Kuwait Oil Company (KOC) as an attachment with M/s Kharafi National for past 3 years (2013 to 2015) in health, safety and environment (HSE- S\&EK Team). He was working with $\mathrm{M} / \mathrm{s}$ Kharafi national in project drainage \& sewage services' in KOC from 2009 to 2013 . He was working with $\mathrm{M} / \mathrm{s}$ Kharafi national in project 'Steamflood operations \& maintenance' as project engineer in join operations (KGOC \& Chevron) from 2008 to 2009. 